\title{
SESSENTA ANOS DE RAE: UM ITINERÁRIO DE CRÍTICAS, RESISTÊNCIAS E REINVENÇÕES
}

\author{
Sixty years of RAE: A journey of criticism, resistance and reinvention \\ Sesenta años de RAE: Una trayectoria de críticas, resistencias y reinvenciones
}

Carlos Osmar Bertero' ${ }^{1}$ | carlos.bertero@fgv.br| ORCID: 0000-0001-9813-088X

${ }^{1}$ Fundação Getulio Vargas, Escola de Administração de Empresas de São Paulo, São Paulo, SP, Brasil

\section{RESUMO}

O artigo trata, de maneira reflexiva, do itinerário da revista ao longo dos seus 60 anos de existência, a partir da experiência do autor, que foi ligado à RAE-Revista de Administração de Empresas ao longo dessas décadas. Abordamos seu início como periódico pioneiro de Administração de Empresas ou Negócios, divulgando conceitos, teorias e práticas de origem predominantemente americana, até os dias atuais, em que emerge como revista que deixou para trás a sua origem generalista e passou a enfatizar áreas como Organização e Estudos Organizacionais, Estratégia e Gestão de Recursos Humanos ou Pessoas. No início, um periódico identificado com uma escola de Administração, a FGV EAESP, passou a uma revista nacional, abrigando autores, consultores e editores associados de outras instituições para, atualmente, laborar para fixar-se como periódico internacional, sendo publicado em português e inglês e atendo-se a tópicos contemporâneos majoritariamente de uma vertente crítica. A crescente sofisticação metodológica da revista e os temas publicados colocam-nos muito distantes dos primeiros anos, em que era uma revista que poderíamos considerar provinciana. Não há dúvida de que avançamos. Parabéns e felizes 60 anos à RAE.

PALAVRAS-CHAVE | Internacionalização, management, crítica, Periódico RAE, Gestão-teoria e prática.

\begin{abstract}
This article reflectively deals with the course taken by the journal over the 60 years it has been in existence, based on the author's experience as someone who was been associated with RAE-Revista de Administração de Empresas for all these years. We deal with its beginning as a pioneering periodical of business administration that divulged concepts, theories and practices that are predominantly American in origin, until we reach today when it emerges as a journal that has left behind its generalist origin and has begun to emphasize areas such as Organization and Organizational Studies, Strategy and Human Resources or People Management. Initially as a journal that was identified with a business school, FGV EAESP, it became a Brazilian journal with its own authors, consultants and associate editors from other institutions, and today it is working to establish itself as an international journal that is published in Portuguese and English, and that deals with contemporary topics mostly from a critical perspective. The growing methodological sophistication of the journal and the topics it publishes are a far cry from the early years, when it was a journal we could consider to be provincial. There is no doubt that we have made progress. Congratulations and a happy 60 years to RAE.
\end{abstract}

KEYWORDS / Internationalization, critical, management, RAE journal, management theory and practice.

\section{RESUMEN}

El artículo trata, de manera reflexiva, la trayectoria de la revista a lo largo de sus 60 años de existencia, a partir de la experiencia del autor, que estuvo vinculado a la RAE-Revista de Administração de Empresas durante estas décadas. Abordamos su inicio como una revista pionera de Administración de Empresas o Negocios, difundiendo conceptos, teorías y prácticas de origen predominantemente estadounidense, hasta la actualidad, en la que surge como una revista que dejó atrás su origen generalista y comenzó a enfatizar áreas como Organización y Estudios Organizacionales, Estrategia y Gestión de Recursos Humanos o Personas. Lo que al principio era una revista identificada con una escuela de Administración, la FGV EAESP, se convirtió en una revista nacional, albergando a autores, consultores y editores asociados de otras instituciones y, actualmente, aúna esfuerzos para consolidarse como una revista internacional, publicada en portugués e inglés y que se atiene a temas contemporáneos, en su mayoría de aspecto crítico. La creciente sofisticación metodológica de la revista y los temas publicados nos alejan mucho de los primeros años, en los que era una revista que podríamos considerar provinciana. No cabe duda de que hemos avanzado. jFelices 60 años a la RAE!

PALABRAS CLAVE I Internacionalización, management, crítica, Revista RAE, Gestión teoría y práctica. 


\section{INTRODUÇÃO: UM POUCO DE CONTEXTO}

A RAE-Revista de Administração de Empresas foi uma das primeiras revistas a tratar de Administração em nosso país. Foi precedida pela RAUSP-Revista de Administração da Universidade de São Paulo e pela RSP-Revista do Serviço Público, fundadas em 1947 e 1937, respectivamente. A RAE, iniciada em 1961, celebra, neste ano, o seu sexagésimo aniversário. Como tive a oportunidade e a honra de exercer por duas vezes o cargo de diretor responsável e editor da revista, fui gentilmente convidado pela atual diretora, Maria José Tonelli, a escrever este artigo neste número especial.

A revista foi a primeira dedicada a tratar especificamente de Administração de Empresas. Sua criação deu-se logo após a iniciativa da Fundação Getulio Vargas (FGV) de criar uma escola destinada à gestão empresarial na cidade de São Paulo, o que ocorreu em 1954. Ao lançar uma revista, a Escola de Administração de Empresas de São Paulo (EAESP) procurava criar um periódico que consolidasse sua presença no meio empresarial e acadêmico de São Paulo.

Com o passar dos anos e décadas, a revista consolidou-se, chegou à respeitável condição de sexagenária e sofreu diversas mudanças. Parodiando a biologia, onde os organismos vivos se transformam ao longo do tempo e em interação com seus ambientes, a RAE foi se transformando em interação não mais apenas com o ambiente empresarial e acadêmico paulista, mas tornou-se um periódico de alcance e repercussão nacional e, no momento, caminha para fixar-se no cenário internacional num mundo onde a academia e as empresas também se tornaram multilaterais.

O momento é de todo oportuno para que, sobrepondo-nos ao natural triunfalismo, se aproveite para lançar sobre a revista um olhar reflexivo e ver até que ponto o itinerário do periódico pode nos permitir ver o que se passou com a Administração, especificamente a empresarial, ao longo de seis décadas. Isso não é pouco, pelo fato de que o período contemplado foi um daqueles em que mais transformações ocorreram na história humana. Já foi apontado que os que viveram desde a Segunda Revolução Industrial, iniciada nos Estados Unidos e na Inglaterra ao redor de1880, até os dias de hoje testemunharam transformações em número e natureza que não tiveram precedente na história humana.

Nosso país passou, ao longo do século passado, por transformações que foram as maiores e mais importantes até agora registradas em nossa história. Da América portuguesa, passou-se a uma Monarquia Constitucional Parlamentarista, seguida de uma República Presidencialista. Essas transformações políticas não foram marcadas por substanciais transformações econômicas. O País, ao iniciar-se a Primeira República, ainda exibia uma economia pouco diferente do que havia sido o período colonial. Mas o século XX trouxe substanciais transformações, não só na economia, mas especialmente na sociedade e também na política. Não sendo um iluminista compulsivo, creio que as transformações não são necessariamente sempre melhores.

Sabidamente, emergimos economicamente ao longo do século passado a uma das maiores economias do mundo. Hoje, integramos o G20 e nosso Produto Industrial situa-se entre os maiores, infelizmente hoje em declínio. A RAE nasceu durante esse momento de grande pujança e transformações da economia brasileira, num crescimento capitaneado pelo desenvolvimento industrial, e a Escola da FGV, que a abrigava, criada para educar os novos profissionais de Administração, que deveriam dedicar-se a gerir a Administração privada ou empresarial, e especificamente as empresas industriais.

Este artigo seguirá uma linha livremente reflexiva. Outros textos já trataram da RAE usando metodologias diversas. Registro aqui o trabalho de Favaretto e Francisco (2017), em que uma metodologia de data mining é utilizada, revelando fatos e relações até inesperadas entre autores, e Tonelli (2018), em que a análise de conteúdo de material publicado pela revista e selecionado pela autora é realizada. Servi-me dos dois trabalhos, que me auxiliaram bastante a amadurecer o que a seguir escreverei. E não poderia deixar sem registro meus dois textos por

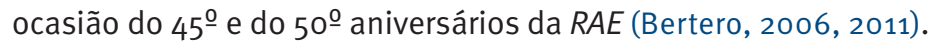


A RAE refletiu e participou de mudanças importantes num campo de conhecimento e ação, caso da Administração, ainda em formação e sabidamente de patrimônio teórico exíguo e volátil. Isso pode ser encontrado ao longo das páginas da revista. Ela começou com um propósito do ponto de vista acadêmico bastante modesto, ou seja, divulgar no País conhecimento sobre uma área ainda emergente, que era a Administração de Empresas ou de Negócios. Não havia preocupação nem expectativa de originalidade ou discussões sobre rigor e relevância. Pressupunha-se que seria relevante publicar em português coisas que, mesmo sem acarretarem novidade para o campo da Administração, nunca tivessem sido publicadas no Brasil. Isso concretiza-se no elevado número de artigos traduzidos, quase sempre da língua inglesa e de publicações americanas, ao longo de muitos anos.

Não havia preocupação em equilibrar conteúdos práticos, que pudessem ser úteis aos profissionais de Administração com textos teóricos, mais de interesse dos escassos acadêmicos que então encontrávamos no País. Não devemos esquecer que o tempo integral para professores no magistério universitário público federal só avançou, alcançando um percentual expressivo de professores, nos anos 1970/80. Em instituições privadas, era praticamente inexistente, salvo raras exceções. Os professores de Administração entre nós, por muito tempo, ainda eram profissionais que dedicavam algumas horas ao ensino ou, posteriormente, professores que viviam exclusivamente do magistério, mas que, para sobreviver, tinham que atuar com frequência até mais de 40 horas semanais em sala de aula. Nada disso poderia caracterizar vida acadêmica como hoje a entendemos.

\section{ALGUNS PONTOS NO ITINERÁRIO DA REVISTA}

A revista nasceu, como a maioria das revistas estrangeiras dedicadas à Administração de Negócios ou Empresas, com um propósito generalista. Várias dessas revistas, ainda hoje, se mantêm como generalistas, caso da Harvard Business Review, da California Management Review e da MIT Sloan Management Review, mas a tendência é que se caminhe para periódicos especializados. Como revista generalista, os primeiros anos da $R A E$ publicaram exclusivamente material referente a Administração de Empresas, e os artigos podiam ser classificados como encaixando-se nas diversas áreas funcionais da Administração. Com a devida liberdade, podemos dizer que tais áreas eram, então, as definidas por Fayol no seu clássico de 1925 (Fayol, 1990).

Mas, ao longo dos anos, a RAE não abandonou uma política editorial generalista, porém tendeu a privilegiar algumas áreas ou funções administrativas mais do que outras. É evidente a tendência de que encontremos um número maior de artigos voltados a Recursos Humanos, Organizações e Estratégia, e menor inserção de artigos dedicados às áreas de Finanças, Contabilidade Gerencial, Operações, Produção e Marketing e Informática. Nas duas ou três décadas iniciais da revista, poder-se-ia dizer que os professores dessas áreas eram mais voltados ao mercado profissional de consultoria, mas isso não é mais verdade para o que acontece após a década de 1990, quando os programas de pós-graduação, especialmente os stricto sensu, incluem professores com dedicação prioritária à docência e à pesquisa para as áreas referidas.

A Escola de Administração da FGV em São Paulo acabou por abrir um programa de graduação em Administração Pública em 1968. Temos, então, um experimento que foi bem-sucedido de manter sob o mesmo teto Administração de Empresas e Administração Pública. Isso levou a que a RAE passasse também a publicar, ao longo das décadas de 1970/80, material de Administração Pública. Mas cabe aqui uma observação. As publicações, bem como a própria natureza dos cursos de Administração Pública na Escola, eram mais voltadas à formulação de políticas públicas do que à gestão pública propriamente. Esses materiais declinam e praticamente desaparecem da RAE à medida que 
surgem periódicos especificamente voltados à área pública, como a RAP-Revista de Administração Publica, ligada à Escola de Administração Pública e de Empresas (EBAPE) da FGV, iniciada em 1967, e Organizações \& Sociedade, ligada ao programa de Administração da Universidade Federal da Bahia, iniciada em 1993.

A Administração não foi a única área a ser publicada pela revista. Administração, em nosso país, é classificada, desde longa data, como uma ciência social aplicada. De que ela seja aplicada, não há dúvida, mas de que seja uma ciência social há muitas dúvidas e reservas entre acadêmicos de Administração e, especialmente, entre os cientistas sociais. Não me parece que economistas, sociólogos, psicólogos sociais, antropólogos, cientistas políticos e historiadores vejam na Administração uma irmã. Talvez uma prima, até em segundo grau para alguns. Mas, como é inegável a proximidade e a mescla e uso de várias ciências sociais para certas áreas que, entre nós, constituem assuntos administrativos, fez com que muitas matérias publicadas possam ser vistas como tipicamente de ciências sociais, portanto poderiam encontrar publicação em periódicos especificamente devotados às ciências sociais respectivas.

Mas essas razões propriamente acadêmicas e até epistemológicas de tentar estabelecer limites e fronteiras entre as diversas ciências e áreas de conhecimento não explicam a razão política para que a RAE abrigasse matérias de ciências sociais durante um certo período. Refiro-me aqui ao período mais sombrio do Regime de Exceção que aqui se estabeleceu, que foi após a edição do Ato Institucional n. 5.0 período foi classificado como o da Ditadura Escancarada (Gaspari, 2014) e, entre todas as repressões e desrespeitos para com os direitos humanos, cabe registrar uma clara perseguição às ciências sociais, que fez com que até a comunidade acadêmica internacional temesse pelo futuro das ciências sociais no País. Isso levou à censura e ao temor que passou a circundar autores e editores de periódicos acadêmicos de ciências sociais.

Devido à postura "tecnocrática" da FGV, suas escolas e periódicos foram relativamente preservados durante o sombrio momento. E isso fez com que a RAE pudesse abrigar material relativo a ciências sociais, especificamente economia, que continha críticas à política econômica do governo militar.

0 momento nacional registrou simultaneidade entre o período mais sombrio da ditadura e o que os governantes autoproclamaram como o "milagre econômico", quando a economia brasileira registrou taxas sem precedentes de crescimento do Produto Interno Bruto, superiores a 10\%. Mas, em tal cenário, a oposição ao regime não dispunha de veículos para expressar-se, uma vez que toda a imprensa, falada e escrita, encontrava-se censurada. E é conveniente lembrar aos mais jovens que ainda não tínhamos, nos anos 1960/70, a web e os onipresentes telefones celulares. Periódicos acadêmicos também estavam sujeitos a ser incomodados por censores do regime.

A revista publicou matéria econômica, tratando do tópico distribuição de renda, que era a crítica mais contundente e, na época, percebida como a única a ser feita contra a política econômica vigente, que era o aumento relativo da pobreza, por haver inegável concentração de renda.

0 assunto da concentração de renda é atualmente matéria corriqueira em literatura econômica e de outras ciências sociais, e ocupa, inclusive, os economistas liberais ou neoliberais. Mas o tema era considerado, no período mais sombrio da ditadura, claramente subversivo, com todas as conotações e ameaças que tal adjetivação significava naquele momento.

Passado aquele momento e, em seguida, o encerramento do período ditatorial, a RAE não deixou de ocupar-se com ciências sociais. Seus conteúdos passaram a acolher materiais que poderiam igualmente encontrar publicação em periódicos dedicados às diversas ciências sociais.

A Administração de Empresas ou de Negócios tem sido apresentada como chegando ao Brasil a partir de uma influência decisiva americana. Muito se tem escrito e refletido, entre autores brasileiros, sobre a palavra Management e seu significado. Chegamos a ter até acaloradas críticas em que se prega o abandono definitivo 
do Management americano e suas repercussões para encontrarmos, também, defensores que o enxergam como realmente bem-vindo e significando racionalidade, eficiência, eficácia e a promessa de uma Administração de melhor qualidade a serviço da sociedade.

Sem adentrarmos esse debate, seria equivocado tomar o Management como a única influência sobre a formação de um campo acadêmico e profissional da Administração no Brasil. Cabe se registrarem outras influências e, entre elas, cabe ressaltar as que vieram da Europa. Em ordem decrescente de importância, mencionaríamos o Reino Unido e a França. A importância da França é revista em artigo que está sendo publicado simultaneamente na $R A E$, de autoria de Jean-François Chanlat, sobre a influência francesa em nosso país. Ela é inegável e foi a maior entre as influências vindas da Europa até a década de 1950. A influência avassaladora dos Estados Unidos só se fez sentir a partir dos anos 1950/60 e ligada ao poderio daquele país como superpotência mundial. Esse movimento acarretou igualmente um triunfo da língua inglesa, que passou a ser praticamente uma língua franca para a academia e para o uso profissional. No Brasil, o francês desapareceu rapidamente, e hoje não é mais adotada como a principal língua estrangeira, ainda que os pensadores franceses tenham inegável impacto na Academia Brasileira de Administração.

No caso da RAE, é importante lembrar que as áreas de Organizações/Estudos Organizacionais e as disciplinas propedêuticas Sociologia, Economia, Psicologia, Ciência Política e, mais recentemente, Filosofia foram lecionadas na Escola de Administração da FGV em São Paulo por professores brasileiros que tiveram sua formação integralmente no Brasil nas áreas respectivas. Essas áreas, no Brasil e particularmente em São Paulo, foram implantadas no ensino superior a partir de missões universitárias francesas, baseadas na Universidade de São Paulo a partir da década de 1930/40, ou seja, desde os primeiros momentos da criação daquela universidade. Portanto, a marca de uma formação francesa está presente nas ciências sociais brasileiras, e isso se manifesta nos artigos predominantemente de orientação crítica das publicações da RAE.

A EAESP foi analisada como o resultado de um processo iniciado pela missão universitária americana da Michigan State University, que para cá trouxe uma concepção da gestão de empresas inteiramente identificada com o Managment americano, mas que, posteriormente, hibridizou-se com influências francesas e inglesas (Alcadipani \& Bertero, 2014).

A governança da RAE também merece atenção. Iniciou-se como um periódico da FGV EAESP e publicando material quase exclusivamente de professores da escola. Gradualmente, foi ampliando o universo de autores abrangendo docentes de outras instituições nacionais. Apenas a partir do final dos anos 1990 é que, claramente, se ergue a questão de expansão do horizonte da revista e fazê-la parte de um projeto de internacionalização. Isso levou a que se debatesse e, finalmente, se passasse a publicar textos eventualmente em inglês, e atualmente estamos diante de uma revista bilíngue, onde todo o material publicado aparece em português e inglês.

Ainda com relação à governança, a revista criou, ainda no final do século passado, um Conselho Editorial, que passou também a ser integrado por membros de outras instituições, tanto brasileiras como de outros países. Por longo período, a revista tinha apenas um diretor, que era também o editor e responsável pela gestão da revista. Era apoiado por professores que atuavam como consultores, dando pareceres e sugerindo publicação ou rejeição. Foram os antecessores dos atuais referees, que têm um papel mais complexo e, frequentemente, podem chegar quase à condição de coautores anônimos de muito do que é publicado. Nessa linha, a revista aderiu à prática internacional, que chegou ao Brasil no final do século passado, de submeter todo o material a ser publicado a pelo menos uma double blind review. Entre os referees, incluíram-se professores de outras instituições nacionais e também de outros países. 


\section{EM CONCLUSÃO: A RAE HOJE}

O que é a RAE hoje? Uma importante revista de Administração, não necessariamente ligada apenas a Administração de Empresas, mas incluindo, também, organizações sociais ou do terceiro setor e, eventualmente, matérias provenientes de ciências sociais que fazem fronteira com a Administração ou que são utilizadas pela Administração como instrumentos de análise e fontes de inspiração. Ocupa, na classificação de periódicos realizada pela CAPES, a qualificação $A 2$, o que a reconhece como periódico de nível internacional. Embora não possua informação sobre a seletividade e a quantidade de submissões versus publicações, infiro que deva ser elevada, chegando a mais de uma dezena de submissões para cada artigo publicado. Isso indica o prestígio da revista e a busca por publicação em suas páginas de parte dos membros da comunidade acadêmica.

Editorialmente, também, atualizou-se, adicionando ao editor-chefe um conjunto de editores associados que não só o auxiliam com o elevado número de submissões, mas também se tornaram necessários devido à especialização da área e à impossibilidade de que uma única pessoa domine o amplo espectro que hoje constitui a área de Administração/Gestão.

Certamente, a RAE pode ser vista como refletindo e, simultaneamente, participando da criação de um campo acadêmico de Administração e, na sua origem, também influindo na prática da Administração, dirigindo-se à comunidade de profissionais de Administração (Tonelli, 2018). É truísmo, mas de afirmação necessária, reconhecer que a área de Administração sofreu muitas transformações e, consequentemente, a RAE, no seu conteúdo, acabou por fazer opções diante de todas as mudanças ocorridas.

Uma importante mudança na área foi o aumento da distância entre a academia e o mundo de profissionais de Administração. Isso levou a dicotomia não necessária entre rigor e relevância. Mas devemos reconhecer que é um problema difícil e sério que uma área que se pretende de prática e academicamente considerada uma ciência social aplicada enfrente tal situação. Nas áreas aplicadas, tomemos Engenharia, Medicina, Odontologia, entre outras, não se pode conceber um brilhante acadêmico que não seja igualmente um competente praticante daquilo que ensina e pesquisa. Ninguém imaginaria um cirurgião de tórax que nunca tivesse realizado cirurgias ou um ginecologista que nunca tivesse tocado uma mulher. Nessa encruzilhada e diante da inevitável dicotomia, a RAE é hoje menos envolvida com prática e aplicações do que foi nas décadas iniciais de sua existência. Deve-se reconhecer que isso ocorreu por causa das orientações dos autores e também pelas pressões que surgiram na área, em que os critérios de avaliação de periódicos científicos acabaram por ser fator importante na construção do fosso entre a teoria e a prática.

A revista, nos primeiros momentos de sua publicação, buscava compor números que fossem equilibrados, com artigos e resenhas cobrindo as várias áreas funcionais da Administração. Isso foi tendendo ao desaparecimento com a concentração de artigos mais nalgumas áreas (Organizações e Estudos Organizacionais, Estratégia e Recursos Humanos) do que noutras. Igualmente, verificou-se uma preocupação com a edição de números tópicos que acabaram por gerar o Fórum. Todavia, não existe uma regularidade na publicação de um Fórum. Isso depende de decisão do diretor responsável, de editores associados ou de iniciativas de acadêmicos que se voluntariam para coordenar um tópico específico. Mas, ao fim e ao cabo, a RAE é atualmente uma revista menos voltada à prática ou à gestão e mais à publicação do material que se encaixe no que é exigido para ser ranqueada como periódico científico segundo padrões internacionais. Claramente, o que é prático, aplicado ou gerencial perdeu espaço relativo na revista.

Acredito que poucos discordariam de que o Brasil é um país anacrônico. E a RAE, durante as duas primeiras décadas de existência, poderia, talvez, ser vista como periódico que não publicava necessariamente a vanguarda. 
Mimetizava o que vinha de fora, majoritariamente dos Estados Unidos. A partir do final do século passado, a RAE deixou de ser um periódico divulgador e passível de anacronismo para se tornar uma publicação divulgadora de temas, problemas e questões de fato contemporâneas para a Administração. Isso se reflete igualmente no cuidado com as metodologias utilizadas para a geração dos artigos que se publicam e na própria temática. De fato, acho que não seria exagero afirmar que os primeiros números são documentos e testemunhos históricos, mas podem ser também entendidos como frestas para que se vislumbre um museu da Administração.

A revista internacionalizou-se. A inserção internacional passou a ser parte da política educacional brasileira. Programas governamentais e os critérios de avaliação gerados pela CAPES e pelo CNPq e outras organizações estaduais e locais que fomentam a pesquisa pressionaram e ainda pressionam pela internacionalização. Isso inclui, como linha de frente desse processo, os periódicos. A RAE passou a publicar material de autores estrangeiros, incluiu professores de outros países como referees, designou estrangeiros para o seu Conselho Editorial e tem organizado Fóruns com a participação de organizadores e autores estrangeiros. Todavia, internacionalizar não é tarefa fácil para um periódico de um país que ainda é visto como mais periférico do que central na atual estratificação internacional. E o português é uma barreira no processo de internacionalização 0 português é uma das línguas mais faladas do mundo em número de parlantes, mas majoritariamente analfabetos funcionais. 0 português não é claramente uma língua de cultura. Entenda-se por isso uma língua que se apreende independentemente do interesse que se possa ter pela história, literatura e cultura dos que falam a língua. Mas a RAE superou essa barreira, tendo se tornado uma revista bilíngue.

Uma característica importante na $R A E$, hoje, é que ela tem como traço distintivo publicar matérias que são de natureza crítica. A hibridização da Escola que a abriga acabou por marcar a revista. Antes de influências diretas vindas da Europa em oposição ou complementação, dependendo do caso, da influência americana, a revista já teve colaboradores que se fixaram como claramente de um conteúdo crítico. Autores como Henrique Rattner, Mauricio Tragtenberg, Fernando Claudio Prestes Motta e Luiz Carlos Bresser-Pereira publicaram nas duas primeiras décadas de existência da revista. Essa tendência acentuou-se com o passar dos anos, e hoje podemos afirmar que um traço distintivo do periódico é a adoção de uma postura crítica, publicando conteúdos que se enquadram na apresentação que encontramos no site da Divisão CMS-Critical Management Studies da Academy of Management.

Desde sua origem até recentemente, a Academy of Management era indiscutivelmente americana e portadora do mainstream do Management americano. Mas, gradualmente, a Academy mudou, iniciando um processo de internacionalização, e hoje ainda carrega traços de sua origem, mas já engloba pessoas do mundo inteiro. E foi dessa maneira, receptiva a autores de outros países e culturas, que também passou a abrigar, em seus diversos comitês e eventos, pessoas que se distanciavam e mesmo se opunham ao chamado mainstream. Nesse contexto, acabou-se caminhando para a criação de uma divisão que abrigasse participantes da Academy representando as diversas tendências críticas. Outro desdobramento foi a criação de um espaço crítico nas diversas revistas publicadas pela Academy of Managment. Mas, pode-se dizer, a RAE foi pioneira ao debater criticamente os princípios e práticas da Administração de Empresas.

A lista de tópicos que pertencem a uma abordagem crítica em Administração e Gestão inclui questões de gênero, com ênfase em tópicos próprios do feminismo, que busca igualdade de condições efetivamente entre os gêneros. Igualmente, questões de homossexualidade e transexualidade. Esses tópicos envolvem a participação de mulheres e a questão LGBTQ+ no mundo da Administração. Sabidamente, ainda que hajam avanços, existe um forte preconceito para aceitação desses grupos em posições de comando, tanto na linha executiva como em assessorias nas organizações. 
A Revista apresenta artigos com críticas ao mundo empresarial, especialmente à maneira como são geridas atualmente as grandes sociedades anônimas ou corporações, voltadas prioritariamente aos acionistas e considerando, por vezes, marginalmente outros stakeholders como empregados, consumidores, fornecedores e a comunidade.

Como coluna mestra de suas estratégias, privilegiar acionistas pode resultar e tem resultado em práticas que não contribuem necessariamente ao bem-estar social e à sustentabilidade, seja da sociedade, do ambiente ecológico ou das próprias empresas e do sistema econômico em médio e longo prazos.

A postura crítica tem adotado atitude de reservas e contestação com teorias organizacionais e estratégias de negócios que se apoiam majoritariamente em sociologias do tipo funcionalista e doutrinas econômicas liberalizantes. A abordagem crítica não tem poupado o projeto globalizador, levando a que se adotem abordagens mais recentes, como o pós-colonialismo.

Também caberia observar a abordagem crítica da área de Recursos Humanos ou Gestão de Pessoas, que tem norteado muitas das publicações da $R A E$ nos últimos anos. Há uma grande reserva com relação ao tratamento de seres humanos como recursos produtivos, e apela-se em oposição ao conceito de gestão não de recursos, mas de pessoas. Isso leva a que se revejam as relações entre superiores/subordinados e também entre pares no local de trabalho e, claramente, à questão das minorias étnicas e também culturais. Nessa área de gestão de pessoas, vista criticamente, pode ser observado o cruzamento de vários preconceitos como obstáculo a carreiras e promoções, discriminação salarial, discriminação nos processos de seleção e avaliação de desempenho contra minorias étnicas, culturais e devido a gênero.

O que me resta dizer, para finalizar, é que só podemos cumprimentar a atual direção da RAE e seus editores associados, os que têm colaborado como referees, o corpo gerencial da revista e os muitos autores e autoras que escreveram para que a revista vivesse e continuasse a viver ao longo de 60 anos. Que ela continue a expressar e moldar os caminhos da Gestão por um longo futuro.

\section{REFERÊNCIAS}

Alcadipani, R., \& Bertero C. O. (2014). Uma escola norteamericana no ultramar? Uma historiografia da EAESP. RAERevista de Administração de Empresas, 54(2), 154-169. doi: 10.1590/So034-759020140204

Bertero, C. O. (2006). A RAE nos seus quarenta e cinco anos. RAERevista de Administração de Empresas, 46(2), 114-117. doi: 10.1590/S0034-75902006000200008

Bertero, C. O. (2011). Meio século de RAE. RAE-Revista de Administração de Empresas, 51(3), 224-226. doi: 10.1590/ So034-75902011000300002

Favaretto, J. E. R., \& Francisco, E. R. (2017). Exploração do acervo da RAE-Revista de Administração de Empresas (de
1961 a 2016) à luz da bibliometria, Text Mining, Rede Social e Geoanálise. RAE-Revista de Administração de Empresas, 57(4), 365-39o. doi: 10.1590/s0034-759020170407

Fayol, H. (1990). Administração industrial e geral: Previsão, organização, comando, coordenação e controle. São Paulo, SP: Editora Atlas.

Gaspari, E. (2014). A ditadura escancarada. Rio de Janeiro, RJ: Editora Intrínseca.

Tonelli, M. J. (2018). Revistas científicas em Administração: 0 papel histórico da RAE-Revista de Administração de Empresas na construção do campo acadêmico em Administração no Brasil. Cadernos EBAPE, 16(Edição Especial). doi: 10.1590/1679-395173941

\section{CONTRIBUIÇÃO DO AUTOR}

O autor declara que realizou todas as etapas de desenvolvimento do estudo. Desde a conceitualização, a revisão teórica (levantamento de literatura), e por fim, redação e revisão final do artigo. 